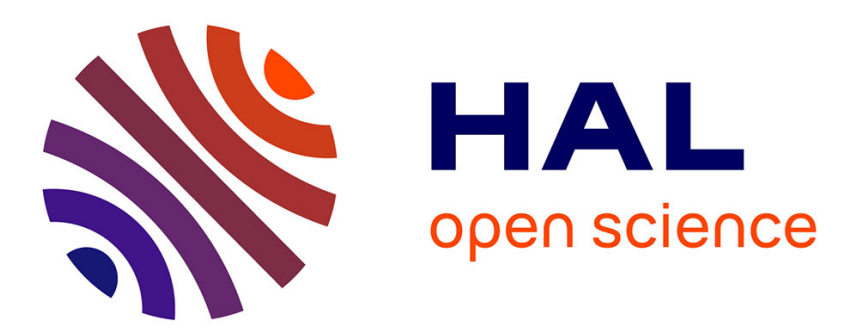

\title{
Porous carbon as catalyst support for CO oxidation: Impact of nitrogen doping
}

\author{
Mangesh Avhad, Valérie Flaud, Laurence Burel, Julie Cavailles, Tushar
}

Sakpal, Leon Lefferts, Helena Kaper

\section{- To cite this version:}

Mangesh Avhad, Valérie Flaud, Laurence Burel, Julie Cavailles, Tushar Sakpal, et al.. Porous carbon as catalyst support for CO oxidation: Impact of nitrogen doping. Carbon, 2020, 169, pp.297-306. 10.1016/j.carbon.2020.07.066 . hal-02991050

\section{HAL Id: hal-02991050 \\ https://hal.umontpellier.fr/hal-02991050}

Submitted on 7 Jan 2021

HAL is a multi-disciplinary open access archive for the deposit and dissemination of scientific research documents, whether they are published or not. The documents may come from teaching and research institutions in France or abroad, or from public or private research centers.
L'archive ouverte pluridisciplinaire HAL, est destinée au dépôt et à la diffusion de documents scientifiques de niveau recherche, publiés ou non, émanant des établissements d'enseignement et de recherche français ou étrangers, des laboratoires publics ou privés. 


\section{Porous carbon as catalyst support for $\mathrm{CO}$ oxidation: impact of nitrogen doping}

Mangesh Avhad, ${ }^{1}$ Valérie Flaud, ${ }^{2}$ Laurence Burel, ${ }^{3}$ Julie Cavailles, ${ }^{1}$ Tushar Sakpal, ${ }^{4}$ Leon Lefferts, ${ }^{4}$ Helena Kaper ${ }^{1 *}$

${ }^{1}$ Ceramic Synthesis and Functionalization Laboratory (LSFC), UMR 3080, CNRS/Saint-Gobain CREE, Saint-Gobain Research Provence, 550 avenue Alphonse Jauffret, Cavaillon, France

${ }^{2}$ Institut Charles Gerhardt Montpellier, UMR 5253 CNRS-UM-ENSCM, Université de Montpellier, Place Eugène Bataillon, F-34095 Montpellier Cedex 5, France

${ }^{3}$ Université Claude Bernard Lyon 1, CNRS, IRCELYON, 2 Av. Albert Einstein, 69626 Villeurbanne, France

${ }^{4}$ Catalytic Processes and Materials, Institute of Nanotechnology, Faculty of Science and Technology, University of Twente, 7522 NB Enschede, The Netherlands

\footnotetext{
*Helena Kaper, phone: +3343250 0895 Email: helena.kaper@saint-gobain.com
} 


\begin{abstract}
Carbonaceous materials are abundant, affordable and simple to implement for a wide range of applications. Its utilization as catalyst support for oxidation reactions seems counter intuitive due to the instability of carbonaceous materials under depollution conditions. The current research work demonstrates that the properties of carbon as support can be fine-tuned via the introduction of heteroatoms. The effect of N-doping together with the anchoring of platinum nanoparticles on the catalytic performance is systematically studied. Factors influencing the performance for $\mathrm{CO}$ oxidation are elucidated using X-ray scattering, $\mathrm{N}_{2}$ physisorption, transmission electron microscopy, elemental analysis, Raman spectroscopy, X-ray photoelectron spectroscopy, temperature programmed reduction and thermogravimetric analysis. The doping of nitrogen in the carbon framework improves the stability of the carbon support, while adding nitrogen and oxygen improves the stability and performance. Doped carbonaceous materials can be a promising support for low and medium temperature range applications $\left(100-250^{\circ} \mathrm{C}\right)$.
\end{abstract}

\title{
1. Introduction
}

Carbon-based materials indubitably will shape our future in the field of energy and environmental technology. They have gained enormous scientific and commercial interest with increasing applications in the separation processes, smart electronic devices, gas- and energy storage, and catalysis [1,2]. The reason is their unique structural features, excellent chemical stability, good thermal conductivity, low density, and of course their availability from a wide range of renewable natural resources [2]. Carbonaceous materials have also found their entry in the field of air and gas stream depollution [3]. For example, preferential carbon monoxide (CO) oxidation is required in generating a clean stream of hydrogen $\left(\mathrm{H}_{2}\right)$ using fuel cell technology [4,5]. 
Abatement of environmental pollutants is of high relevance as the polluted air is indeed a great threat to human health and its constant exposure even at ppm level can lead to severe diseases [6]. The efficiency of different materials as adsorbents and catalysts for the removal of air pollutants has been successfully tested $[7,8]$. In general, the catalyst-assisted oxidation reaction of volatile organic pollutants can be advantageous over adsorbent techniques because of drawbacks associated with restricted efficiency and the need for regeneration treatment and/or disposal [9]. Carbonaceous materials have been tested as catalyst support for a variety of chemical processes owing to their stability in acidic and basic medium [10,11], but find limited appliance for oxidation reaction because of their poor stability under aerobic conditions. Also, poor interaction between the metal catalyst and the carbon surface leads to the deactivation of the final catalyst due to either leaching and sintering of metal nanoparticles or breakdown of the carbon framework at elevated temperature $[12,13]$.

The current research study is primarily focused on strengthening of the metal-support interaction by modifying the physicochemical characteristics of carbonaceous materials. It has been reported that the support material plays a vital role not only in influencing the performance of catalytic materials but in certain cases also for the overall oxidation reaction mechanism [1416]. For instance, ceria is a well-known support for platinum (Pt) group metal for oxidation reactions not only because of its excellent redox properties and oxygen storage capacity [17-20], but also strong interaction between the noble metal and ceria[18,21,22]. Here we want to study the influence of $\mathrm{O}-$ and $\mathrm{N}$ - heteroatoms on the platinum nanoparticle stability and $\mathrm{CO}$ oxidation performance. One of the problems when using carbon as a support is the formation of small size metal nanoparticles (NPs) and maintaining their size and stability on the carbon support, especially under oxidation reaction conditions. For example, one of the reasons for the deactivation of 
Pt/activated carbon (AC) catalyst applied to formaldehyde oxidation is the agglomeration and leaching of metal NPs [12]. This concern turns out to be even more critical when the catalytic system is used for long reaction hours and repeated oxidation cycles. A potential solution to restrict the metal catalysts leaching and agglomeration is the incorporation of the metal-support interaction system in carbon-based catalysts.

The incorporation of heteroatoms, such as nitrogen, in carbonaceous materials alters the interaction between metal nanoparticles and support as well as the stability of the final catalytic system under oxidation reaction conditions. Wang et al. resume in a recent review article the importance of N-doping of carbon materials in heterogeneous catalysis.[23] Earlier works already describe surface functionalization of carbon materials with different heteroatoms as a tool to alter its physicochemical properties [24-27]. Carbon nitrides $\left(\mathrm{g}-\mathrm{C}_{3} \mathrm{~N}_{4}\right)$ and nitrogen-doped carbon materials are currently gaining enormous attention due to their improved thermal and chemical stability, electric conductivity, and water-splitting potential $[28,29]$. The different electron density between carbon and nitrogen boosts the metal-support interaction as the nitrogen moieties available in carbon support acts as tethers for metal NPs. Xiao et al. report an improved stability and dispersion of Pt- and gold NPs on $g-\mathrm{C}_{3} \mathrm{~N}_{4} / \mathrm{SBA}-15$ composites due to the strong interaction between metal and polymeric carbon nitrides as compared to pure SBA-15 [30]. Xing et al. [12] suggest that Pt lixiviation can be significantly minimized after the surface functionalization of AC with nitrogen-rich species. In their work, the authors use melamine as a nitrogen source for the surface functionalization, improve the metal-support interactions and reduce the particle size of the catalyst. However, only a maximum of 3.1 at. \% of nitrogen incorporation is reported despite the high specific surface area $\left(\mathrm{S}_{B E T}: 1241 \mathrm{~m}^{2} \mathrm{~g}^{-1}\right)$ of the material. This rather limited degree of heteroatoms integration onto carbon is due to post-synthesis functionalization presumably on the 
external surface of the material. Recently, $\mathrm{Pu}$ et al. synthesized porous N-doped carbon using dicyandiamide and MOFs as precursors.[31] This way, the authors obtained $10 \mathrm{wt}-\%$ of $\mathrm{N}$ content and successfully dispersed Pd nanoparticles on the surface. The degree of nitrogen inclusion into the carbon matrix using the surface functionalization route is difficult to control. While it is certain that the synthesis technique is the key, the degree of nitrogen incorporation controls the metalsupport interaction. Together with a highly porous structure, the material can provide a high number of binding sites to augment the dispersion and stability of metal nanoparticles. Therefore, a systematic evaluation of the above-mentioned features is of foremost importance in order to clearly evaluate the proficiency of lucrative carbon-based materials for catalytic oxidation processes.

The current study demonstrates that metal-support interaction is vital for porous carbon supported catalytic materials and the thermal oxidative stability of carbons improve by controlled doping of nitrogen into the support framework. The catalytic proficiency of Pt supported on highly porous carbons, with varied nitrogen content, is systematically investigated by using $\mathrm{CO}$ oxidation as a model reaction. This is to the best of our knowledge the first report scrutinising the effect of nitrogen-doped porous carbons (NPCs) as support for Pt catalyst for CO oxidation, on catalytic performance, stability and recyclability.

\section{Experimental}

\subsection{Synthesis}

Porous carbons were synthesized via colloidal silica assisted sol-gel process by adapting a synthesis described in the literature [27]. The carbon precursor, phenol-formaldehyde resins, was prepared in a polypropylene bottle. The nitrogen incorporation inside the carbon matrix is 
performed using melamine (99\%, Sigma-Aldrich) as a nitrogen source. Following a reported synthesis protocol [27], calculated amounts of phenol (P: $39 \mathrm{mmol}$; 99\%, Merck) and formaldehyde solution (F: $78 \mathrm{mmol} ; 37 \mathrm{wt} . \%$, Sigma-Aldrich) were added gradually to $100 \mathrm{ml}$ $\mathrm{NaOH}$ solution ( $0.2 \mathrm{M}, 10 \mathrm{mmol} ; 99 \%$, Merck) under continuous stirring. The mixture is stirred at room temperature at $250 \mathrm{rpm}$ for 20 minutes, and then the synthesis temperature is raised to 70 ${ }^{\circ} \mathrm{C}$ for 40 minutes. Next, an appropriate amount of melamine (M) and an additional amount of formaldehyde solution (107 mmol) was added. The carbon samples with M:P of 0.5:1 and 2:1 are denoted as LNPC (low nitrogen-containing porous carbon) and HNPC (high nitrogen-containing porous carbon), respectively. The mixture was continuously stirred at $250 \mathrm{rpm}$ for 30 minutes. Then, $50 \mathrm{~g}$ of Ludox SM-30 (30 wt. $\%$ colloidal $\mathrm{SiO}_{2}$ in water, Merck) was added to the above solution and the mixture was continued heating at $70{ }^{\circ} \mathrm{C}$ under stirring for 60 minutes. The bottle containing the suspension was then sealed and heated at $80{ }^{\circ} \mathrm{C}$ for 3 days without stirring. The semi-solid polymer was crushed and dried at $80{ }^{\circ} \mathrm{C}$ overnight. The dried brownish powder was ground and sieved to have a particle size of less than $250 \mu \mathrm{m}$. The dried polymer was carbonized under nitrogen at $800^{\circ} \mathrm{C}$ for 3 hours using the heating rate of $5^{\circ} \mathrm{C}$ per minute. The obtained black powder is then subjected to $250 \mathrm{ml} \mathrm{NaOH}(2 \mathrm{M})$ treatment at $80^{\circ} \mathrm{C}$ with stirring at $250 \mathrm{rpm}$ for 12 $\mathrm{h}$ to remove the $\mathrm{SiO}_{2}$ template. The materials were then washed with water to neutralize the $\mathrm{pH}$ value and dried at $80^{\circ} \mathrm{C}$ for $12 \mathrm{~h}$. The NPCs with different nitrogen contents were synthesized by varying the M:P molar ratio. For the synthesis of porous carbon doped with nitrogen as well as oxygen (LNOPC), glucose (G: $3.51 \mathrm{~g}$; Analar Normapur, VWR Chemicals) is used as an oxygen source along with melamine ( $2.46 \mathrm{~g})$ as the nitrogen source. The porous carbon (PC) was prepared using the above-mentioned protocol without the addition of a nitrogen or oxygen source. 
The Pt deposition on as-synthesized carbon supports was performed by wet impregnation. The support, carbon, is added to $100 \mathrm{ml}$ water and sonicated for 20 minutes. A calculated amount of $\mathrm{Pt}$ precursor (platinum nitrate hexahydrate, $59.14 \% \mathrm{Pt}$, Heraeus), dissolved in water, was added dropwise and the mixture was sonicated for 20 minutes followed by heating at $80^{\circ} \mathrm{C}$ for $6 \mathrm{~h}$ under continuous stirring. Finally, water is removed using the rotational evaporation. The final catalyst is dried in an oven at $80^{\circ} \mathrm{C}$ for $12 \mathrm{~h}$.

\subsection{Characterization}

X-ray scattering analyses at a wide angle (WAXS) and small angle (SAXS) of as-synthesized samples were recorded on an X'Pert diffractometer from PANanalytical Instruments equipped with $\mathrm{CuK}_{\alpha}$ monochromatic radiation source ( $45 \mathrm{kV}$ and $\left.40 \mathrm{~mA}\right)$ and $\mathrm{X}^{\prime}$ Celerator detector working in Bragg-Brentano geometry. The acquisition was carried out between $10^{\circ}$ and $80^{\circ}$, step width $0.1^{\circ}, 85 \mathrm{~s} /$ step. Nitrogen $\left(\mathrm{N}_{2}\right)$ adsorption/desorption isotherms were acquired at $-196{ }^{\circ} \mathrm{C}$ with a Micromeritics Tristar II 3020 analyzer, after degassing the samples under vacuum at $200{ }^{\circ} \mathrm{C}$ for 12 hours. The specific surface area (SSA) was calculated using the Brunauer-Emmet-Teller (BET) method and the pore size distribution was determined from the desorption branch of the isotherms using the the Barrett-Joyner-Halenda (BJH) method. The thermal oxidative stability of carbons was measured using a thermogravimetric analysis (TG96, Setaram) using heating rate of $5{ }^{\circ} \mathrm{C} \mathrm{min}{ }^{-}$ ${ }^{1}$ and airflow of $50 \mathrm{~mL} \mathrm{~min}^{-1}$. The carbon, hydrogen, and nitrogen content of materials is analysed using Thermo Scientific Flash 2000 organic elemental analyser equipped with a thermal conductivity detector. Hydrogen-temperature-programmed reduction $\left(\mathrm{H}_{2}-\mathrm{TPR}\right)$ profiles for the samples are obtained using AutoChem 2920 (Micromeritics). Raman spectra are collected using Thermo Scientific Raman spectrometer DXRxi with laser beam operating at $532 \mathrm{~nm}$, laser power of $5 \mathrm{~mW}$, exposure time of $200 \mathrm{~ms}$ and microscope offering 4 levels of magnification. The obtained 
data through TPR and Raman analyses were normalized using Origin software and presented for better comparison of the results. X-ray photoelectron spectroscopy (XPS) analysis is performed using a Thermo Electron ESCALAB 250 equipped with a monochromatic Al Ka X-ray source $(1486.6 \mathrm{eV})$. The analysed surface has a diameter of $500 \mu \mathrm{m}$. The binding energies were calibrated based on the $\mathrm{C} 1 \mathrm{~s}$ peak at $284.4 \mathrm{eV}$. The Pt metal content in the catalytic samples was verified using inductively coupled plasma (ICP) spectrometer (Thermo Fischer Scientific iCAP6300 ICP-OES). Transmission electron microscope (TEM) imaging is performed on TEM Jeol 2010. The images are analysed using the ImageJ software. The platinum particle size dispersion was determined by counting around 200 platinum particles per sample, taking into account at least three different areas of the sample.

\subsection{Catalytic activity measurements}

The catalytic $\mathrm{CO}$ oxidation reaction is carried out in a continuous mode fixed bed set-up integrated with a U-shaped quartz reactor, furnace, and gas analyser. The length and the diameter of the reactor bed are 37 and $20 \mathrm{~mm}$, respectively. The temperature of the catalyst bed was monitored by a thermocouple located next to the catalyst bed. The gas stream from the separator was discharged through a back-pressure controller that maintained constant pressure of 1.0 MPa. The total gas flow rate passing through the reactor is always $10 \mathrm{nlh}^{-1}$. Approximately $100 \mathrm{mg}$ of catalyst powder is placed in the reactor. The catalysts are reduced using $40 \% \mathrm{H}_{2}$ diluted in $\mathrm{He}$ at $200^{\circ} \mathrm{C}$ with a flow rate of $10 \mathrm{nlh}^{-1}$ for a total time of 77 minutes. The light-off experiments for CO oxidation are performed using a heating ramp of $2^{\circ} \mathrm{C} / \mathrm{min}$ from room temperature to reaching 300 ${ }^{\circ} \mathrm{C}$ with a plateau of 10 minutes. Each run is repeating three times without any intermediate treatment. The $\mathrm{CO}$ oxidation is performed using $2000 \mathrm{ppm}$ of $\mathrm{CO}$ and $3000 \mathrm{ppm}$ of $\mathrm{O}_{2}$. The gases were analysed using micro-gas chromatography SRA R3000 instrument coupled with a TCD 
detector and equipped with two columns, MolSieve5APLOT and Column PLOT U. Each measurement takes two minutes.

For the thermal stability tests, the pure carbon materials are heated at $10{ }^{\circ} \mathrm{C} / \mathrm{min}$, reaching a temperature of $350{ }^{\circ} \mathrm{C}$ in the presence of oxygen $(3000 \mathrm{ppm})$.

\section{Results and Discussion}

\subsection{Structural characteristics of carbon}

Carbon materials with different nitrogen and oxygen content are prepared by controlling the molar ratio of dopants (M: melamine, G: glucose) to phenol $(\mathrm{P})$ in the polymeric resins. In the following, carbon samples with a ratio of M:P equal to 0.5 and 2 are denoted as LNPC (low nitrogen-containing porous carbon) and HNPC (high nitrogen-containing porous carbon). Pure porous carbon is denoted as PC and LNOPC describes porous carbon derived from $(0.25 \mathrm{M}+0.25 \mathrm{G}): 1$ (see also Table 1$)$. Table 1 gives the elemental composition of the different porous carbonaceous materials determined using $\mathrm{CHN}$ analyses. The amount of nitrogen can indeed be regulated through the addition of a calculated amount of melamine in the polymeric resin. While the undoped carbon contains only $0.1 \mathrm{wt}-\%$ of nitrogen, LNPC contains already 3.0 wt- $\%$ and HNPC 8.7 wt- $\%$ of nitrogen.

Table 1: Structural properties and elemental composition of carbon materials. $\mathrm{M} / \mathrm{P}$ indicates the ratio of melamine and phenol precursor, $\mathrm{PV}$ : pore volume, $\mathrm{PD}$ : Pore diameter, $\mathrm{I}_{\mathrm{D}} / \mathrm{I}_{\mathrm{G}}$ : Intensity ratio of the D- and G band. 


\begin{tabular}{|l|l|l|l|l|l|l|l|l|l|}
\hline \multirow{2}{*}{ Sample } & $\mathrm{M} / \mathrm{P}$ & \multirow{2}{*}{$\begin{array}{l}\mathrm{S}_{\mathrm{BET}} \\
\left(\mathrm{m}^{2} \mathrm{~g}^{-1}\right)\end{array}$} & $\begin{array}{l}\mathrm{PV} \\
\left(\mathrm{ccg}^{-1}\right)\end{array}$ & $\begin{array}{l}\mathrm{PD} \\
(\mathrm{nm})\end{array}$ & $\begin{array}{l}\mathrm{N} \\
(\mathrm{wt} . \%)\end{array}$ & $\begin{array}{l}\mathrm{C} \\
(\mathrm{wt} . \%)\end{array}$ & $\begin{array}{l}\mathrm{H} \\
(\mathrm{wt} . \%)\end{array}$ & $\begin{array}{l}\mathrm{O}^{\alpha} \\
(\mathrm{wt} . \%)\end{array}$ & $\mathrm{I}_{\mathrm{D}} / \mathrm{I}_{\mathrm{G}}$ \\
\hline PC & 0 & 1081 & 3.4 & 13 & 0.1 & 94.4 & 1.0 & 4.5 & 1.14 \\
\hline LNPC & 0.5 & 1107 & 3.2 & 10 & 3.0 & 79.9 & 1.2 & 15.9 & 1.04 \\
\hline HNPC & 2 & 1218 & 3.9 & 12 & 8.7 & 77.8 & 1.0 & 12.5 & 1.09 \\
\hline $\begin{array}{l}\text { LNOP } \\
\mathrm{C}\end{array}$ & $0.5^{\beta}$ & 1408 & 2.4 & 6.0 & 1.5 & 76.7 & 1.4 & 20.4 & 1.06 \\
\hline
\end{tabular}

$\alpha:$ Normalized values; $\beta: \mathrm{M} / \mathrm{P}=(0.25)+\mathrm{G} / \mathrm{P}=(0.25)$

The applied carbonization temperature of $800{ }^{\circ} \mathrm{C}$ under nitrogen leads to disordered amorphous carbonaceous materials, as confirmed by WAXS analysis. The obtained x-ray scattering patterns of as-synthesized LNOPC, HNPC, LNPC and PC are presented in Figure 1a. A broad peak at $23.7^{\circ}$ and a weaker, broad peak at $43.7^{\circ}$ corresponding to the (002) and (100) planes of graphite lattice is observed for all carbon materials. The inclusion of heteroatoms in the carbon matrix does not affect the position of both peaks, which is in agreement with the results from Chen et al.[27] The graphitic nature of the carbonaceous materials is further analysed using Raman spectroscopy, and the spectra for PC, LNPC, HNPC and LNOPC are presented in Figure $1 \mathrm{~b}$. Distinctive D- and G-bands, located at $1333( \pm 2)$ and $1578( \pm 3) \mathrm{cm}^{-1}$, are observed in all cases, representing the disordered structure of graphitized carbons. The D-band signifies defects in the carbon framework, while the G-band corresponds to the graphitic nature of carbons. Figure $1 \mathrm{~b}$ shows that the incorporation of heteroatoms does not affect the position of the two bands. The intensity ratios of the D-band to the G-band $\left(\mathrm{I}_{\mathrm{D}} / \mathrm{I}_{\mathrm{G}}\right)$ decrease when adding nitrogen to the porous 
carbon, but is relatively insensitive to the amount of nitrogen added (Table 1). This indicates that the carbon materials become slightly more graphitic when adding nitrogen.

a)

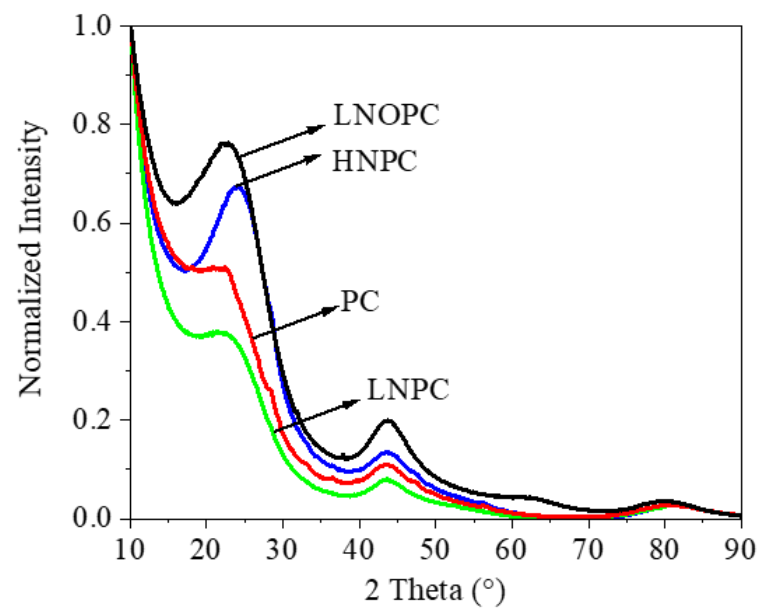

b)

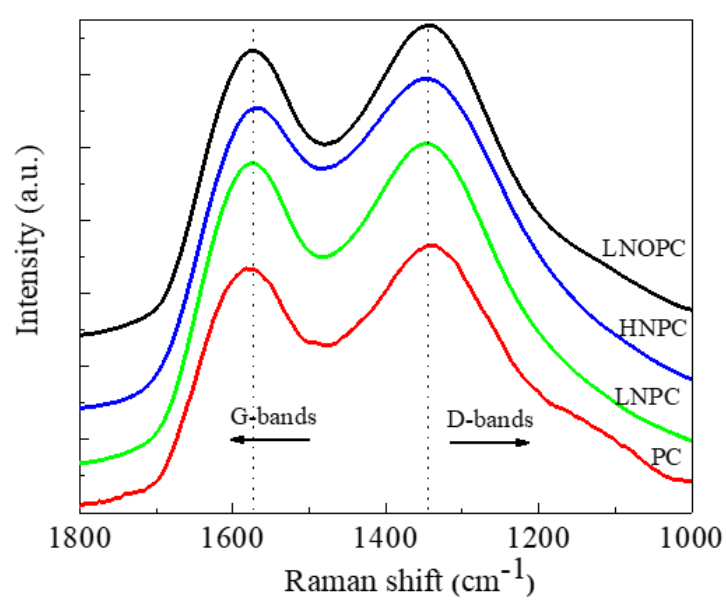

Figure 1: Structural characterization of un-doped porous carbon (PC), low nitrogen-doped porous carbon (LNPC), high nitrogen-doped porous carbon (HNPC) and nitrogen- and oxygen-doped carbon (LNOPC): a) Wide angle X-ray scattering and b) Raman spectroscopy.

We use colloidal $\mathrm{SiO}_{2}$ (Ludox SM-30) to increase the surface area. The presence of a disordered pore structure and the amorphous nature of all carbon materials are identified by an irregular SAXS patterns (supplementary Figure $\mathrm{S} 1)$. The specific surface area $\left(\mathrm{S}_{B E T}\right)$, pore volume (PV) and pore diameter (PD) are calculated from $\mathrm{N}_{2}$-physisorption desorption branch, and the measured values for different carbon materials are listed in Table 1. All materials show high specific surface areas (SSA) above $1000 \mathrm{~m}^{2} / \mathrm{g}$, which augments with increasing nitrogen doping level (LNPC: $1107 \mathrm{~m}^{2} / \mathrm{g}$; HNPC: $1218 \mathrm{~m}^{2} / \mathrm{g}$ ). The highest SSA is obtained for combined nitrogen and oxygen doping (LNOPC: $1408 \mathrm{~m}^{2} / \mathrm{g}$ ). The average PD for the nitrogen doped samples is 
around $12 \mathrm{~nm}$, which is bigger than the size of single silica nanoparticle (8nm), possibly because of aggregation of the latter. In contrast, the PD for combined nitrogen and oxygen doping is lower (LNOPC: $6.9 \mathrm{~nm}$ ). As shown in Figure 2a, nitrogen-doped porous carbon and un-doped porous carbon materials show typical type IV isotherms with $\mathrm{H} 2$ hysteresis loops suggesting the presence of both micropores and mesopores in graphitized carbons. In comparison, the LNOPC sample shows a H4 hysteresis loop suggesting possible slit-like pores with voids of irregular shape. The above-mentioned behaviour indicates that melamine and glucose impact the final material differently. The pore size distributions are shown in the supplementary Figure S2. For PC, the pore size distribution is rather wide, whereas for HNPC and LNPC, we observe one distribution around $10 \mathrm{~nm}$ and a broader peak starting from $20 \mathrm{~nm}$. Interestingly, LNOPC shows only one pore size around $10 \mathrm{~nm}$, indicating that glucose impacts the synthesis and resin formation. The porous structure of carbon materials is further studied using TEM analysis (Figure 2b). The wall thickness is approximately $1.3 \mathrm{~nm}$, and the measured pore size is in good agreement with that determined using $\mathrm{N}_{2}$-desorption analyses. 
a)

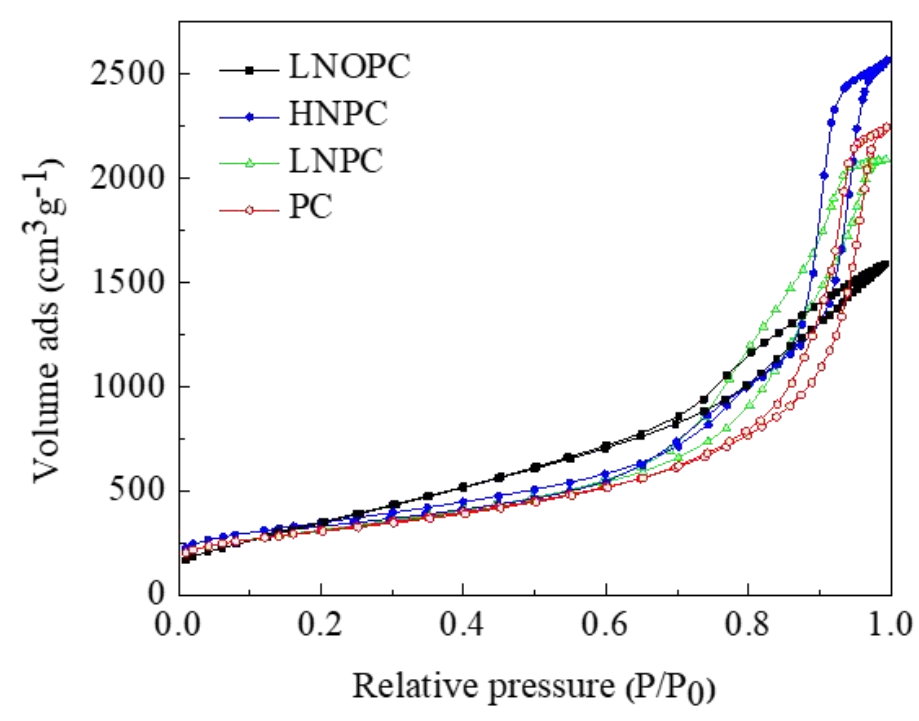

b)

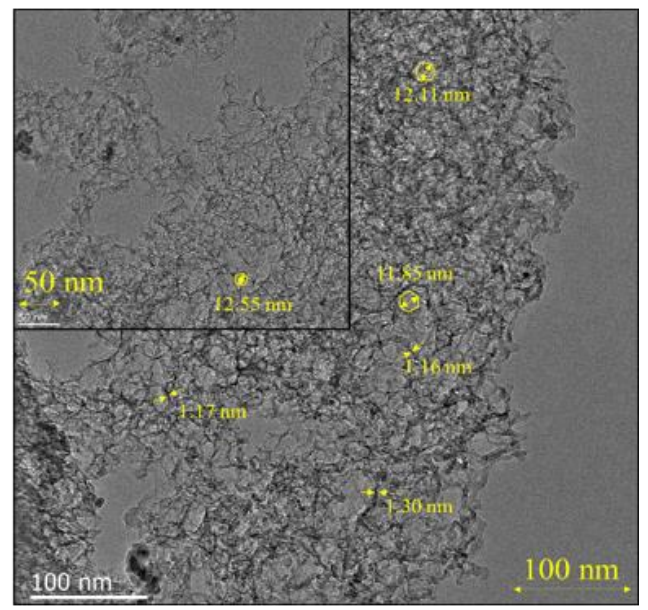

Figure 2: a) Nitrogen physisorption isotherms of PC, LNPC, HNPC and LNOPC. b) TEM image of LNPC.

The atomic composition and the chemical bonding within the carbon matrix are further studied using XPS analysis, examples are shown in Figure 3. As seen, the addition of glucose and/or melamine does influences the oxygen and nitrogen functionalities. Carbon and oxygen are detected in the survey scan of LNOPC, HNPC, and PC (Figure 3a). A peak at $400 \mathrm{eV}$, assigned to N1s, is clearly visible in HNPC, whereas this peak is notably smaller for LNOPC and PC. The asymmetric C1s peak observed at a binding energy of $284.4 \mathrm{eV}$ corresponds to the graphitized carbon (supplementary Figure S3). The deconvolution of C 1s spectrum for PC (Figure 3b) indicates the presence of four different bands: single bound carbon to oxygen as in ethers and phenols (C-O, $286.1 \mathrm{eV})$, double-bound carbon to oxygen as in ketones and quinones $(\mathrm{C}=\mathrm{O}, 287.5 \mathrm{eV})$, carbon bound to two oxygen atoms as in carboxyl groups, carboxylic anhydrides and esters (-COO, 287.7 $\mathrm{eV})$, and the characteristic shakeup line of carbon in aromatic compounds ( $\pi-\pi^{*}$ transition).[32] 
There is a good agreement in the literature on the assignment of the peaks in the $\mathrm{N} 1 \mathrm{~s}$ spectra of HNPC (Figure 3c).[33] Deconvolution gives $41 \%$ of pyridinic N $(397.9 \mathrm{eV}), 13.5 \%$ pyrrolic or pyridone $\mathrm{N}(399.2 \mathrm{eV}), 38.0 \%$ of quaternary or graphitic $\mathrm{N}(400.4 \mathrm{eV})$ and $7.5 \%$ of pyridine oxide at $402.5 \mathrm{eV}$. The fact that $\mathrm{N}$ is not directly bound to oxygen, as for example in $\mathrm{N}=\mathrm{O}$ bonds (404-408 eV), shows that nitrogen atoms are bonded with carbon atoms and therefore stabilize the carbon network. The relative quantities of different energy levels for carbon materials are listed in supplementary Table S1. As shown in Figure 3d, the deconvolution of the O 1s spectrum in the case of LNOPC results into three peaks. The peak centred at a binding energy of $531.16 \mathrm{eV}$ is assigned to carbonyl oxygen ( $\mathrm{O}=\mathrm{C}$ in quinones, ketones and aldehydes), 532.90 refers to ether or phenol $\mathrm{O}(\mathrm{C}-\mathrm{O}-\mathrm{C}$ or $\mathrm{C}-\mathrm{OH})$ and the third peak at $535.15 \mathrm{eV}$ is designated as carboxylic O.[32] The deconvolution of the C 1s peak of HNPC and LNOPC are given in the supplementary Figure S4 and Figure S5. The deconvolution of the N 1s peak for PC, LNPC, HNPC and LNOPC are given in the supplementary Figure S6 and Figure S7. In general, the same species are present in $\mathrm{PC}$ as for the $\mathrm{N}$-doped porous carbons, with one exception, the contribution from pyridine $\mathrm{N}$ oxide. 
a)

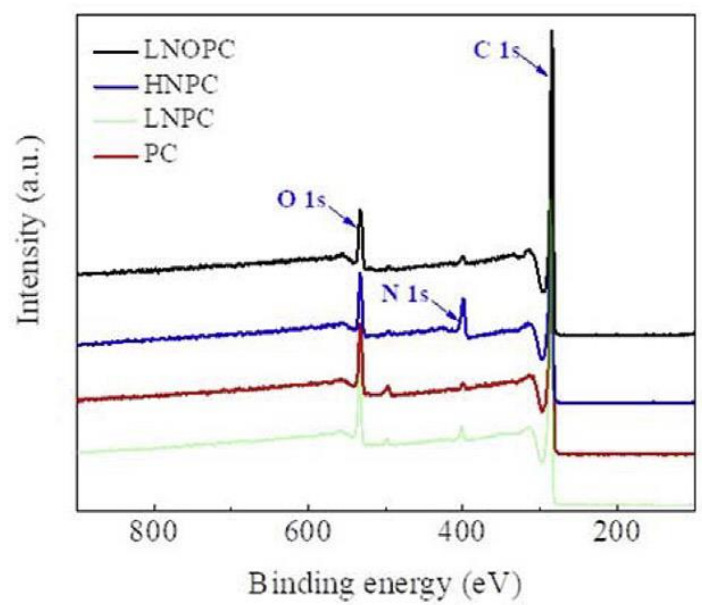

c)

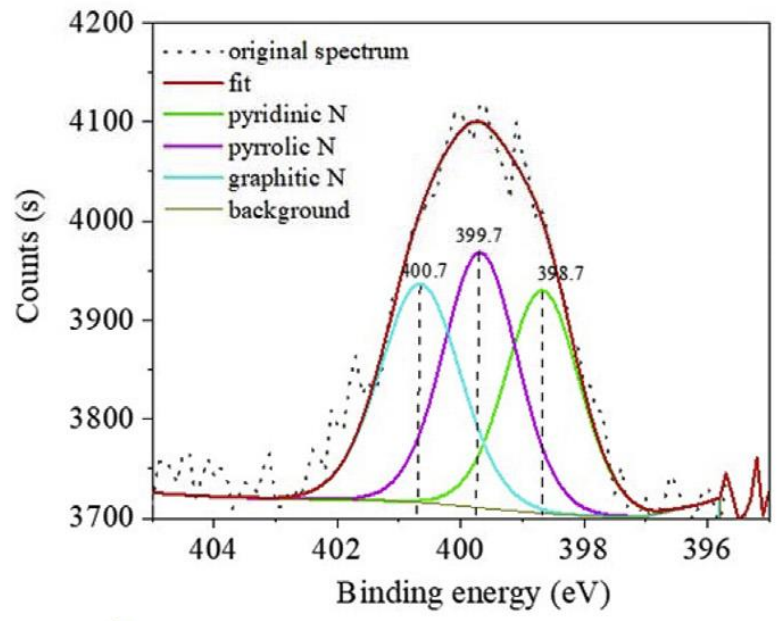

e)

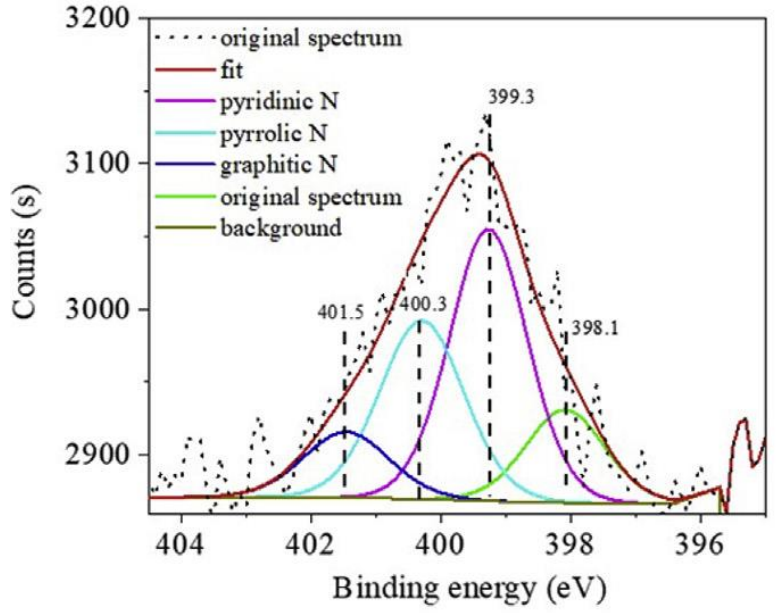

b)

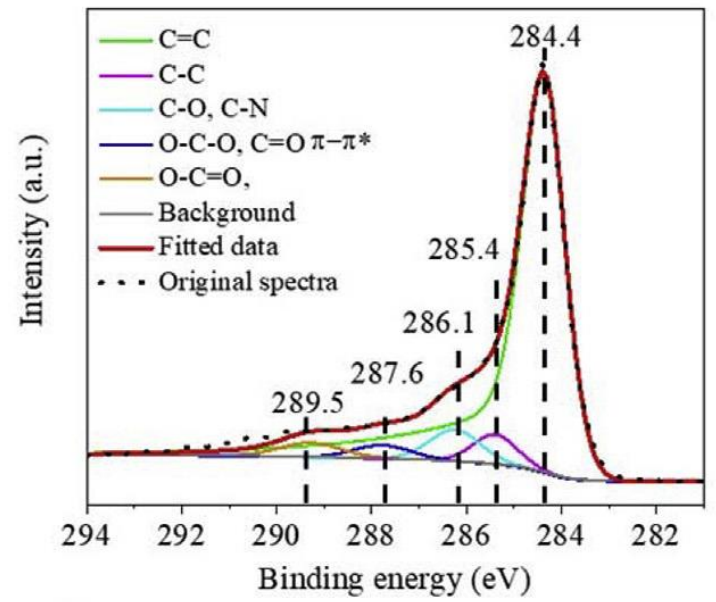

d)

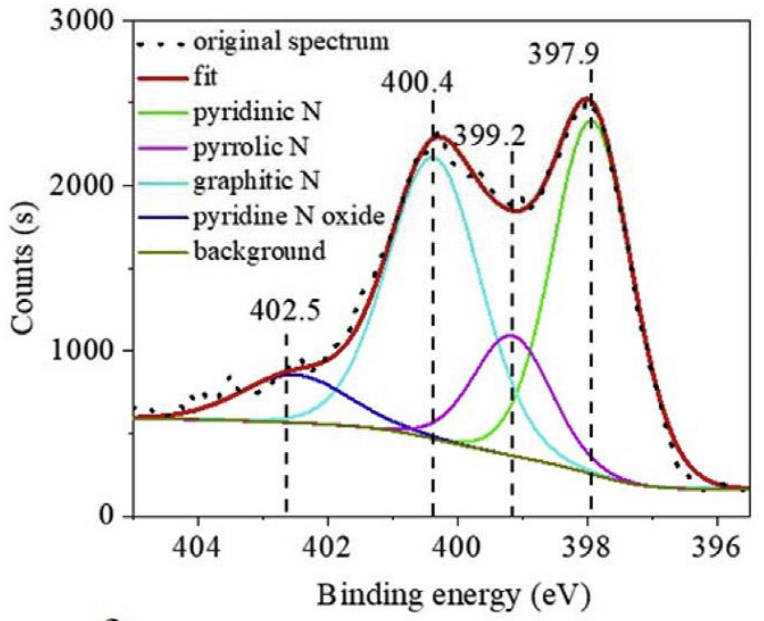

f)

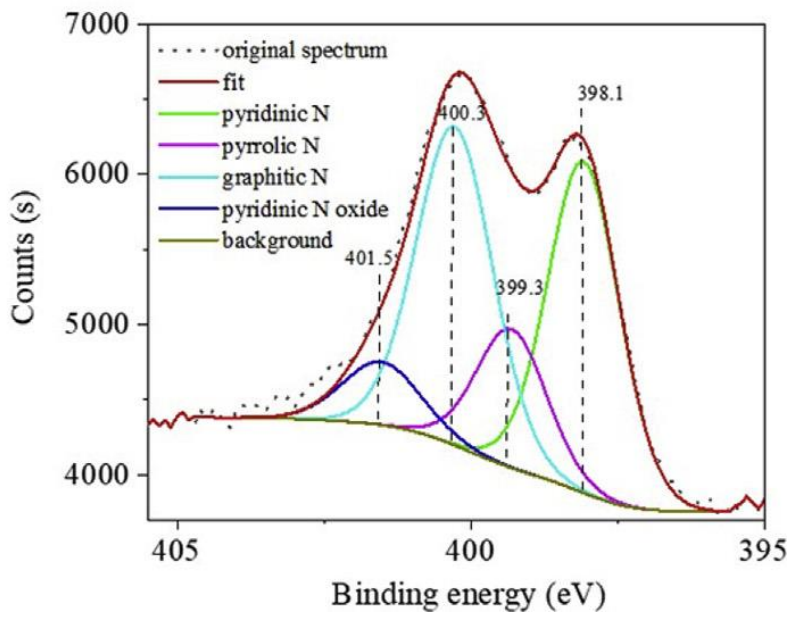


Figure 3: XPS analysis of different carbonaceous materials. a) survey scan of LNOPC, LNPC, HNPC and PC b) High-resolution C 1s XPS spectra for PC, c) N 1s XPS spectra for PC, d) N 1s

XPS spectra for HNPC, e) N 1s XPS spectra for Pt/PC and f) N 1s XPS spectra for Pt/HNPC.

In the following, we study the impact of platinum impregnation on the nitrogen bands and vice versa. Strong interaction between the carbonaceous support and the platinum metal species should result in band shift of the XPS spectra. Indeed, the peak position of graphitic $\mathrm{N}$ and pyridinic $\mathrm{N}$ is shifted upon addition of $\mathrm{Pt}$, as shown in Figure 4. The amplitude of this shift depends on the amount of N-doping, and is most pronounced for HNPC and Pt/HNPC. In this case, the graphitic N band is shifted by $1.36 \_\mathrm{eV}$ to higher energies, and the pyrdinic $\mathrm{N}$ band is shifted by $-1.24 \mathrm{eV}$ to lower bands, indicating on the one hand electron transfer from graphitic $\mathrm{N}$ to the Pt nanoparticles, and on the other hand electron withdrawal from the Pt nanoparticles to pyridinic N (electron acceptor). These results are in good agreement with the literature, where indeed interaction between Platinum nanoparticles and is described: graphitic $\mathrm{N}$ acts as electron donor and pyridinic $\mathrm{N}$ as electron acceptor.[34] This effect is less pronounced for the other carbon materials, probably due to the lower nitrogen content and the shielding of the nitrogen by the Pt nanoparticles during XPS analysis. Secondly, we analyse the Pt oxidation state in the different samples after hydrogen pretreatment. The Pt nanoparticles are in a oxidized state, besides the reduction under hydrogen. We also observe a slight shift of the Pt4f7 A energy level. Going from Pt/PC to Pt/LNPC and Pt/HNPC, the energy level decreases from $71.6 \mathrm{eV}$ to $71.4 \mathrm{eV}$ and $71.19 \mathrm{eV}$, respectively. This shift to lower energy indicates that the electron donation form graphtic $\mathrm{N}$ excels the electron withdrawing from pryridinic $\mathrm{N}$.

The first observation is a decrease of the $\mathrm{N}$-content, in particular of graphitic $\mathrm{N}$ and pyridinic 
N, upon Pt impregnation (see Table S1 and Table S2 for details). For example, HNPC has 2.9 at $\%$ graphitic N and 3.1 at $\%$ pyridinic N, while Pt/HNPC has only 2.8 and 2.7 at $\%$. This decrease hints already towards interaction between nitrogen in the carbon support and the platinum particles, with preferred position of the Pt nano- particles on the nitrogen edges. The effect is most pronounced for LNPC, where Pt nanoparticles cover nearly all the nitrogen. To take a closer look at the band position of the N1S peak, the N 1S XPS spectra of PC, HNPC, Pt/PC and Pt/HNPC are plotted in Fig. 3cef. Indeed, the peak position of graphitic $\mathrm{N}$ and pyridinic $\mathrm{N}$ are shifted upon Pt addition. The amplitude of this shift depends on the amount of N-doping, and is most pronounced for HNPC and Pt/HNPC. The graphitic $\mathrm{N}$ band is shifted by $1.36 \mathrm{eV}$ to higher energies, and the pyridinic $\mathrm{N}$ band is shifted by $-1.24 \mathrm{eV}$ to lower energies, indicating on the one hand electron transfer from graphitic $\mathrm{N}$ to the $\mathrm{Pt}$ nanoparticles, and on the other hand electron withdrawal from the $\mathrm{Pt}$ nanoparticles to pyridinic $\mathrm{N}$ (electron acceptor). These results are in good agreement with the literature: graphitic $\mathrm{N}$ acts as electron donor and pyridinic $\mathrm{N}$ as electron acceptor [34]. This effect

is less pronounced for the other carbon materials, in agreement with the lower nitrogen content and the shielding of nitrogen by the Pt nanoparticles during XPS analysis. Finally, we analyse the Pt oxidation state in the different samples after hydrogen pretreatment (see Table S2 for details). The Pt nanoparticles are in anoxidized state, as the band of Pt 0 is shifted to higher energy levels

$(>71.2 \mathrm{eV})$, despite the reduction under hydrogen. The reoxidatoin of the Pt particles might also be due to their small size and exposure to air after reduction and prior to the XPS measurement. Only for Pt/LNOPC we do not observe a Pf4f7 A band typical for reduced nanoparticles. The high oxygen content of this carbon seems to interact with the Pt nanoparticles, leading to oxidized states only. We also observe a shift of the Pt4f7 A energy level. Going from Pt/PC to Pt/LNPC and $\mathrm{Pt} / \mathrm{HNPC}$, the energy level decreases from $71.6 \mathrm{eV}$ to $71.4 \mathrm{eV}$ and $71.19 \mathrm{eV}$, respectively. This 
shift to lower energy indicates that the electron donation form graphitic $\mathrm{N}$ excels the electron withdrawing from pryridinic N. Altogether, XPS analysis of the N1s peak and Pt $4 \mathrm{f}$ level confirms interaction between platinum nanoparticles with the carbon support and this interaction is modified upon the addition of heteroatoms.

\subsection{Catalytic performance for CO oxidation}

All materials were used as support materials for platinum nanoparticles and tested for $\mathrm{CO}$ oxidation under oxidative conditions. At elevated temperatures and in the presence of oxygen, carbonaceous materials will degrade. Therefore, it is important to assure that the material is stable under the employed conditions. Surprisingly, this aspect, especially when carbon-based catalyst supports are used for oxidation reaction, is rarely discussed. The thermogravimetric weight losses of PC, LNPC, HNPC and LNOPC as a function of temperature under air are presented in Figure 4. The first weight loss between $50^{\circ} \mathrm{C}$ and $120^{\circ} \mathrm{C}$ is likely due to the removal of water and surface adsorbates. A noticeable weight loss in the case of the porous carbons begins from approximately $150{ }^{\circ} \mathrm{C}$ and increases further with rising temperatures. The incorporation of heteroatoms in the carbon matrix improves the oxidation stability of doped materials when compared to the pure carbon, PC. The corresponding mass losses for PC, LNPC, HNPC and LNOPC between 150 and $400{ }^{\circ} \mathrm{C}$ are $13.4,3.1,6.0$ and $3.9 \%$. These measurements indicate that LNPC is the thermally most stable material in air up to $450^{\circ} \mathrm{C}$. This result is in good agreement with recent literature, reporting that a nitrogen content higher than an optimal value promotes the carbon oxidative gasification.[27] In order to assess the impact of Pt on the thermogravimetric stability, thermogravimetric analysis of the materials with and without platinum was carried out for PC and 
LNPC (Figure S8). Indeed, the presence of platinum decreases the stability under air slightly. However, the materials remain stable until $300^{\circ} \mathrm{C}$, well above $\mathrm{CO}$ oxidation temperature.

The thermal stability of carbon materials in the presence of oxygen (3000 ppm) is also examined through monitoring $\mathrm{CO}_{2}$ and $\mathrm{CO}$ production, (supplementary information Figure $\mathrm{S} 9$ and S10). The obtained results are in good agreement with the TGA analysis. Non-doped carbon PC starts to produce $\mathrm{CO}$ and $\mathrm{CO}_{2}$ from $150^{\circ} \mathrm{C}$, and is less stable at higher temperatures $\left(200^{\circ} \mathrm{C}-\right.$ $350^{\circ} \mathrm{C}$ ) when compared with the doped materials. For better comparison, the $\mathrm{CO}_{2}$ and $\mathrm{CO}$ values emitted at $300^{\circ} \mathrm{C}$ for carbon materials are tabulated in the supplementary Table S2. The insertion of heteroatoms improves the thermal oxidative stability of carbon. Indeed, PC emits considerably more $\mathrm{CO}$ and $\mathrm{CO}_{2}$ compared to LNPC, HNPC and LNOPC. The lowest values for emitted CO and $\mathrm{CO}_{2}$ are observed for LNPC and HNPC. When adding O- and N- heteroatoms simultaneously as in LNOPC, intermediate values for $\mathrm{CO}$ and $\mathrm{CO}_{2}$ are obtained.

Next to the thermal stability in air, also the thermal behaviour of different carbon materials under hydrogen atmosphere is of importance because the Pt nanoparticles deposited on carbon are reduced in hydrogen at $200{ }^{\circ} \mathrm{C}$ for 60 minutes before $\mathrm{CO}$ oxidation. All carbon materials are stable under the conditions used for reducing the supported Pt catalysts, as hydrogen consumption of the pure carbons starts only above $650^{\circ} \mathrm{C}$ (see Figure S 11 ). 


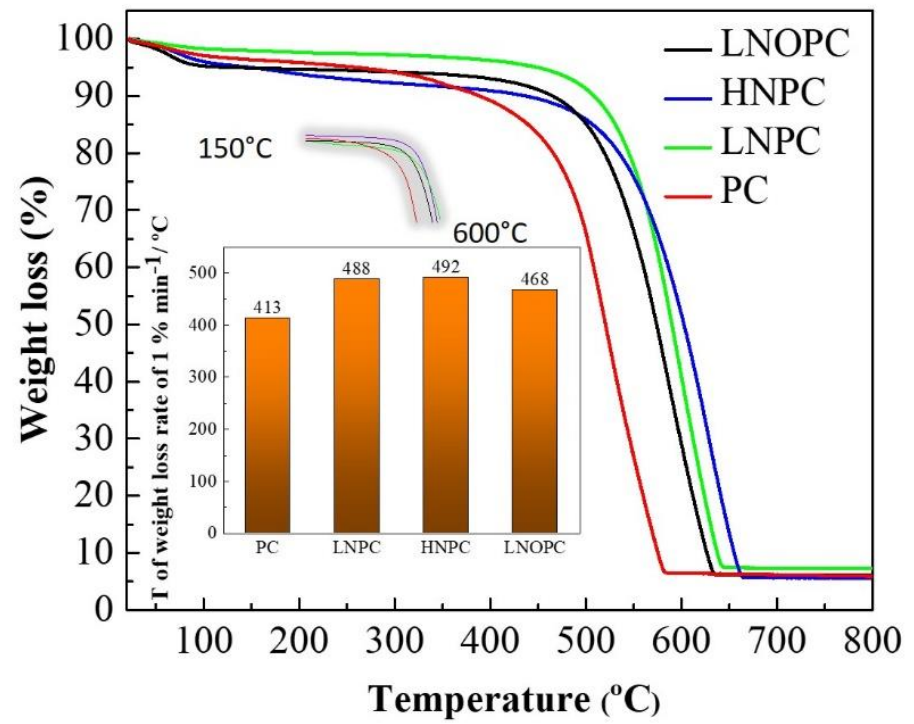

Figure 4: Thermogravimetric analysis under air, heating rate $5^{\circ} \mathrm{C} / \mathrm{min}$.

All carbon supports are impregnated with 1 wt. \% Pt (see experimental section), with subsequent evaluation of the metal content using ICP-OES. The Pt concentration on PC, LNPC, HNPC and LNOPC is 1.04, 0.94, 0.91 and 1.07 wt.\%, which confirms a successful impregnation of $\mathrm{Pt}$ on the supports with the desired amount of platinum. Prior to the first cycle of $\mathrm{CO}$ oxidation, all catalysts are pre-treated under $40 \% \mathrm{H}_{2}$. The second and third consecutive cycles (all up to $300^{\circ} \mathrm{C}$ ) are carried out without intermediate regeneration in order to test the stability of the materials. Figure 5e shows the CO oxidation curves of the first cycle for $1 \mathrm{wt}$ \% Pt on PC, LNPC, HNPC and LNOPC and Figure $5 f$ the corresponding reaction rates. The temperatures required for CO conversion of $10 \%\left(\mathrm{~T}_{10}\right), 20 \%\left(\mathrm{~T}_{20}\right)$ and $50 \%\left(\mathrm{~T}_{50}\right)$ are tabulated in the supplementary information Table $\mathrm{S} 3$. The $\mathrm{T}_{10}, \mathrm{~T}_{20}$ and $\mathrm{T}_{50}$ values are the lowest in the case of LNOPC, followed by PC, LNPC and HNPC supported catalysts. Cycling of the catalyst indicates that $\mathrm{T}_{10}, \mathrm{~T}_{20}, \mathrm{~T}_{50}$ and even $\mathrm{T}_{100}$ values, in the case of PC as support, lower as shown in Figure 5a. Considering the 
thermostability of the PC (Figure 4 and Figure S9 and S10), it is not certain that the observed lower $\mathrm{CO}$ conversion temperature upon cycling is only related to a better catalytic performance or partially due to actual degradation of the material. For the nitrogen-doped carbon species, cycling is rather stable (Figure 5b-d), which goes along with a better thermostability. For the most performing catalyst, Pt/LNOPC, we carried out five consecutive CO oxidation light off curves (Figure $5 \mathrm{~d}$ ). The catalyst is nearly stable after the first run, with only slight changes in the catalytic performance for the subsequent runs.

All carbon materials are analysed also after the catalytic test in order to assess the structural and compositional differences after $\mathrm{CO}$ oxidation. The WAXS pattern after three cycles of CO oxidation are shown in Figure S13. The relative height of the (002) and (100) peaks remains basically unchanged. The most significant change of the carbonaceous materials during $\mathrm{CO}$ oxidation is the specific surface area (Table S4). Even though the decrease in the specific surface area of at least $50 \mathrm{~m}^{2} / \mathrm{g}$ is quite important for all carbonaceous materials, the materials maintain high surfaces areas above $700 \mathrm{~m}^{2} / \mathrm{g}$. The changes in the specific surface area go along with a change in the pore size distribution (see Figure S13). In particular, for PC we observe that the bimodal pore size distribution is reduced to a monomodal distribution centred around $9 \mathrm{~nm}$, indicating a partial collapse of the carbon structure. 
a)

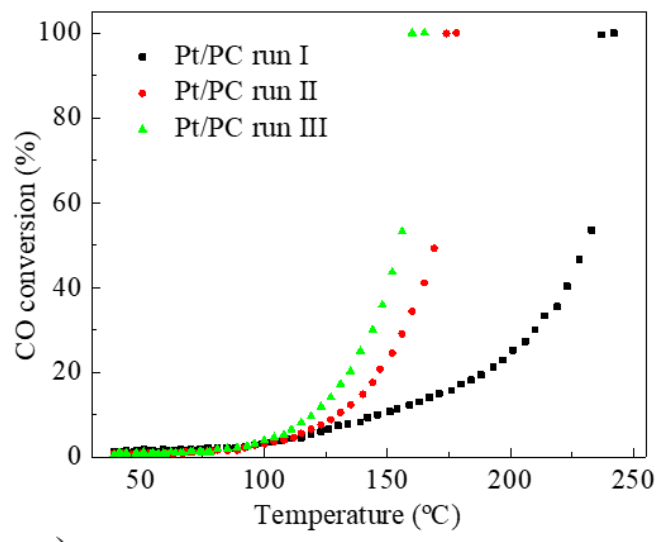

c)

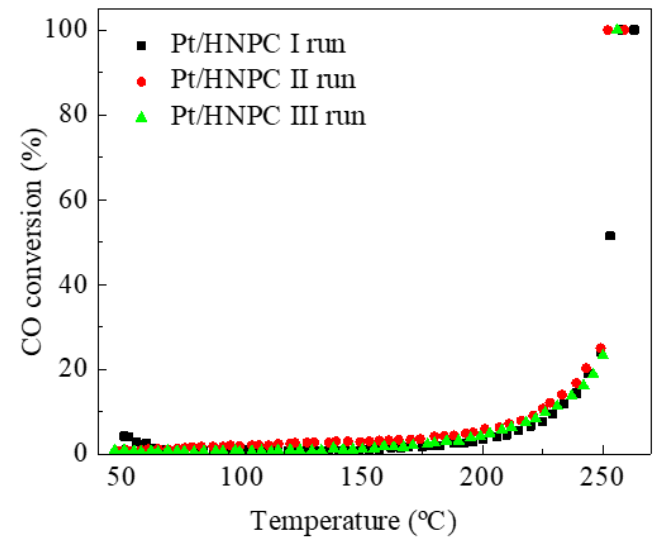

e)

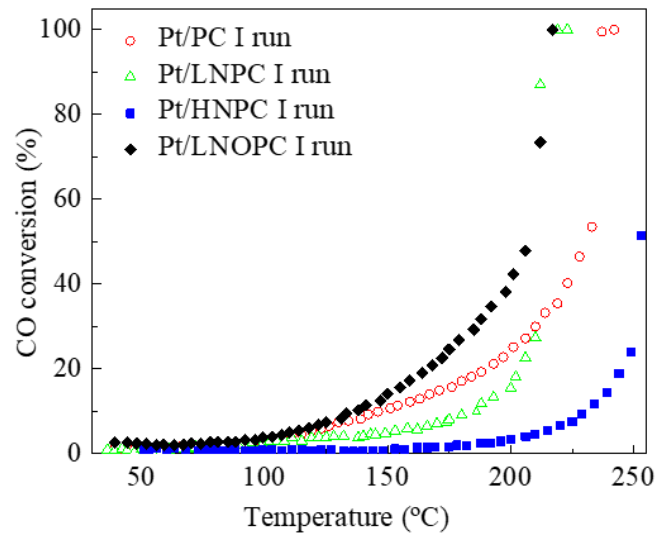

b)
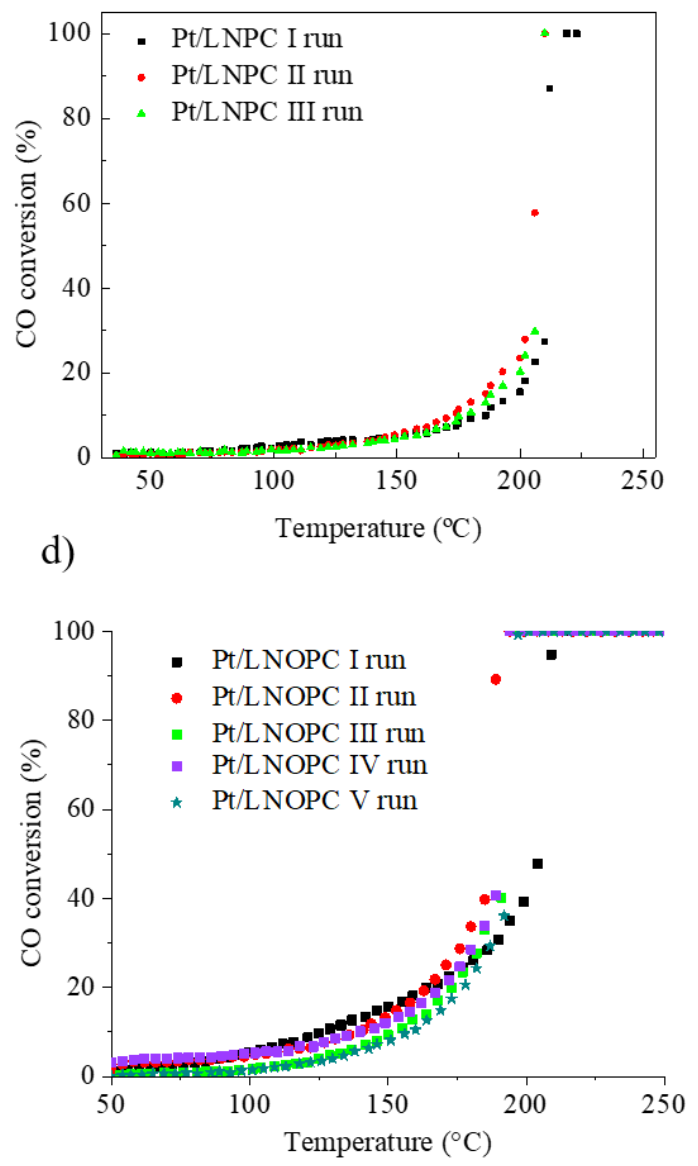

f)

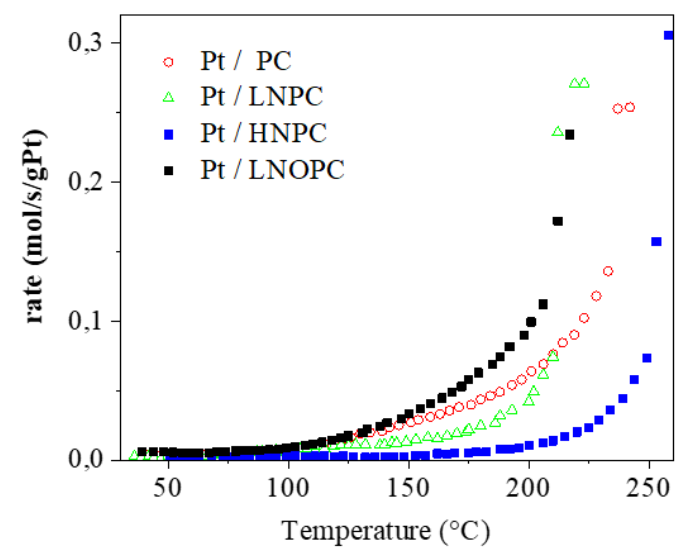

Figure 5: $\mathrm{CO}$ oxidation light-off curves using supported $\mathrm{Pt}$ (1 wt.\%) catalysts. Reaction conditions: $\mathrm{CO}: 2000 \mathrm{ppm}, \mathrm{O}_{2}: 3000 \mathrm{ppm}$, heating rate: $2^{\circ} \mathrm{C} / \mathrm{min}$. a) $\mathrm{Pt} / \mathrm{PC}$, b) $\mathrm{Pt} / \mathrm{LNPC}$, c) 
Pt/LNPC and d) Pt/LNOPC, e) CO conversion of the first cycle for the different carbon supports, f) rates of the first cycle for the different carbon supports.

TEM analysis (Figure 6) of at least 250 particles at three different sample areas gives a platinum particle size of roughly $1 \mathrm{~nm}$ (see Table S4) after test for LNPC, HNPC and LNOPC. Only for PC the particle size is with $3.8 \mathrm{~nm}$ significantly higher, which motivated us to verify the particle size prior to the catalytic test for this sample and one representative $\mathrm{N}$-doped porous carbon, in this case LNPC. Indeed, the particle size of PC is $1.1 \mathrm{~nm}$ prior to the test and $0.95 \mathrm{~nm}$ for LNPC, so the platinum particle size is rather similar prior to the catalytic test. The increase of the platinum particle size for Pt/PC after reaction might also explain the better performance upon cycling. It has been shown in the literature that supported platinum nanoparticles show structure sensitivity for $\mathrm{CO}$ oxidation under oxidative conditions, with bigger particles $(2-3 \mathrm{~nm})$ showing better performance than smaller particles.[35]

These results indicate a trade-off between performance (e.g. Pt/PC reacts at lower temperature than Pt/N-doped PC) versus stability (N-doped carbons preserve their performance upon cycling). To further address the question of performance and stability, stability tests under reactive conditions were carried out for Pt/PC, Pt/LNPC and Pt/HNPC. Figure S12 shows the CO oxidation at $100 \%$ conversion for Pt/PC, Pt/LNPC and Pt/HNPC. Even though all materials are stable for 800 minutes, the performance of Pt/PC decreases after this time, while Pt/LNPC and Pt/HNPC remain stable throughout the measured time. Despite the performance at lower temperature, $\mathrm{PC}$ is less stable and possibly experiences structural fracture under oxidation reaction 
conditions. This is further confirmed by elemental analysis of the spent catalysts (see Table S4). Indeed, the amount of oxygen is strongly increased for PC, while the content of $\mathrm{N}$,

C, - and O remains stable for LNPC, HNPC and LNOPC. The available literature suggests that the nitrogen doping in the carbon matrix increases the number of anchoring sites and strengthen the interaction between the metal catalyst and support.[12,36] As evident from Figure 5c and

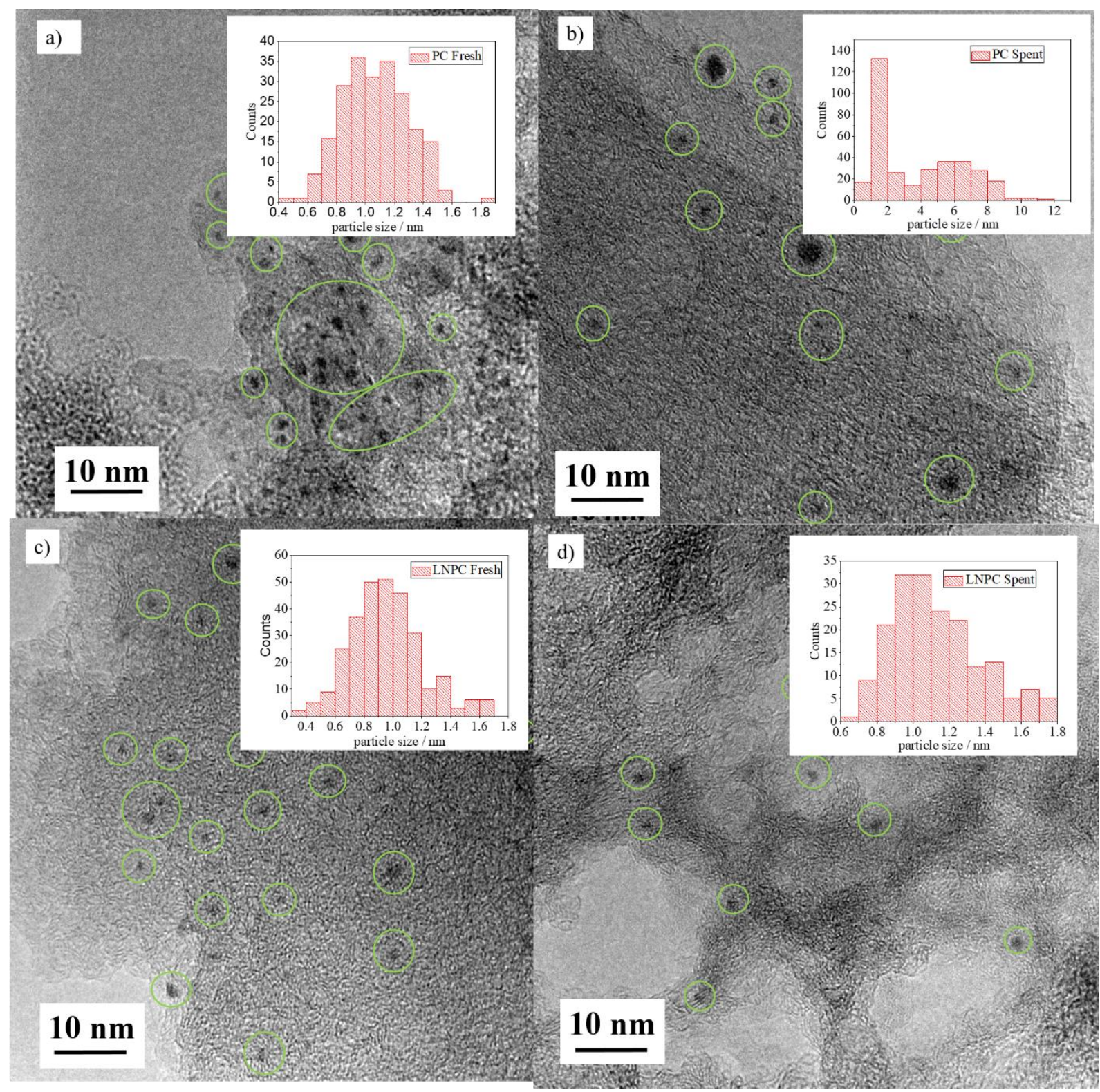


Figure 6 HRTEM images of Pt/PC before (a) and after (b) CO oxidation and of Pt/LNPC before (c) and after (d) CO oxidation. Pt particles are seen as darker points (green circles). Inserts show the Pt particle size distribution.

$5 \mathrm{~d}$, nitrogen doping in the carbon framework enhances significantly the stability of catalyst throughout the three reaction cycles, at the expense of a performance at higher temperature. The stability of the material is also reflected in the platinum nanoparticle size after the catalytic testing. Indeed, for nitrogen-containing carbonaceous materials, the platinum size stays around $1.1 \mathrm{~nm}$. Though it is shown that nitrogen incorporation in the carbon support affects the binding of Pt with support,[12] the amount of $\mathrm{N}$-doping needs to be optimized to give the best performance of the final catalyst.

We further investigate the impact of oxygen species, along with nitrogen, in the carbon framework as $\mathrm{CO}$ oxidation catalyst. The $\mathrm{CO}$ oxidation light-off curves for three reaction cycles using Pt/LNOPC are shown in Figure $5 d$ and the $T_{10}, T_{20}, T_{50}$ and $T_{100}$ values are listed in Table S2. The inclusion of oxygen species in nitrogen-doped carbon is rather beneficial for the performance of platinum catalysts. Although the presence of oxygen moieties positively affects the performance of platinum nanoparticle catalyst, it is worth noticing that LNOPC is slightly more unstable than LNPC as confirmed from thermal analysis (Figure 4 and supplementary information Figure $\mathrm{S} 9$ and $\mathrm{S} 10)$. The production of $\mathrm{CO}_{2}$ under oxygen at $250{ }^{\circ} \mathrm{C}$ from $\mathrm{LNOPC}(159 \mathrm{ppm})$ is slightly higher than that of LNPC (77 ppm). The importance of oxygen species has also been described in the literature. One of the reasons for the lower performance of pure $\mathrm{g}-\mathrm{C}_{3} \mathrm{~N}_{4}$ supported metal catalysts is the absence of oxygen moieties in the support.[13,37] Our results are in agreement with the reported studies,[13,27,38] showing that Pt/LNOPC presents better catalytic performance than Pt/LNPC, and is relatively stable during the three reaction cycles. 


\section{Conclusion}

Improved metal-support interactions and oxidative thermal stability of porous and/or doped carbons are highlighted through the current study, making these materials interesting catalyst supports for e. g. the oxidation of carbon monoxide. The boosted stability of Pt supported carbon catalysts under oxygen reaction atmosphere can be related to the controlled doping of nitrogen in the carbon framework. The nitrogen incorporation affects the physicochemical properties of carbon and its interaction with the Pt catalyst. When the Pt catalyst is supported on LNPC and HNPC, the stability of the Pt nanoparticles is significantly improved and can be effectively utilised for 3 reaction cycles. However, $\mathrm{CO}$ conversion takes place at higher temperature compared to Pt/PC. When adding small amount of oxygen to the nitrogen-doped carbon, an optimized system with respect to performance and stability is obtained, pointing towards a trade-off between stability and performance. This is possibly the first time that carbon-supported noble metal catalysts are used for multiple reaction cycles, which demonstrates the potential future of carbon-based catalytic materials for air depollution process at an intermediate temperature range (up to $250^{\circ} \mathrm{C}$ ), next to application in depollution via adsorption.

Supporting Information. The following files are available free of charge. Small angle x-ray scattering of the carbon materials, Pore size distribution, XPS analysis, 
thermogravimetric analysis, stability tests, $\mathrm{H}_{2}-\mathrm{TPR}$, Table of $\mathrm{CO}$ conversion at $\mathrm{T}_{10}, \mathrm{~T}_{20}, \mathrm{~T}_{50}, \mathrm{~T}_{100}$ $\mathrm{T}_{20}$, elemental analysis after catalytic test (Supporting Information, PDF)

\section{Author Contributions}

The manuscript was written through contributions of all authors. All authors have given approval to the final version of the manuscript.

\section{Funding Sources}

M. A. thanks the Fonds Unique Interministériel for funding under the project "AIRCLEAN".

\section{ACKNOWLEDGMENT}

The authors thank the METSA network for access to TEM measurements.

\section{References}

[1] W. Xin, Y. Song, Mesoporous carbons: recent advances in synthesis and typical applications, RSC Adv. 5 (2015) 83239-83285. doi:10.1039/c5ra16864c.

[2] M.-M. Titirici, R.J. White, N. Brun, V.L. Budarin, D.S. Su, F. del Monte, J.H. Clark, M.J. MacLachlan, Sustainable carbon materials, Chem. Soc. Rev. 44 (2015) 250-290. doi:10.1039/C4CS00232F.

[3] M.S. Mauter, M. Elimelech, Environmental Applications of Carbon-Based Nanomaterials, Environ. Sci. Technol. 16 (2008) 5843-5859.

[4] K. Liu, A. Wang, T. Zhang, Recent Advances in Preferential Oxidation of CO Reaction 
over Platinum Group Metal Catalysts, ACS Catal. 2 (2012) 1165-1178. doi:10.1021/cs200418w.

[5] Y. Zhou, R. Pasquarelli, R. Holme, J. Erry, D. Ginley, R. O’Hayre, Improving PEM fuel cell catalyst activity and durability using nitrogen-doped carbon supports : Observations from model Pt / HOPG systems, J. Mater. Chem. 19 (2009) 7830-7838. doi:10.1039/B910924B.

[6] A.P. Jones, Indoor air quality and health, Atmos. Environ. 33 (1999) 4535-4564.

[7] X.S. Zhao, Q. Ma, G.Q. (Max) Lu, VOC Removal: Comparison of MCM-41 with Hydrophobic Zeolites and Activated Carbon, Energy \& Fuels. 12 (1998) 1051-1054. doi:10.1021/ef980113s.

[8] M. Guillemot, J. Mijoin, S. Mignard, P. Magnoux, Volatile organic compounds (VOCs) removal over dual functional adsorbent/catalyst system, Appl. Catal. B Environ. 75 (2007) 249-255. doi:https://doi.org/10.1016/j.apcatb.2007.04.020.

[9] S.S. Kim, K.H. Park, S.C. Hong, A study on HCHO oxidation characteristics at room temperature using a Pt/TiO2 catalyst, Appl. Catal. A Gen. 398 (2011) 96-103. doi:https://doi.org/10.1016/j.apcata.2011.03.018.

[10] K.N. Iost, V.A. Borisov, V.L. Temerev, Y. V Surovikin, P.E. Pavluchenko, M. V Trenikhin, A.A. Lupanova, A.B. Arbuzov, D.A. Shlyapin, P.G. Tsyrulnikov, A.A. Vedyagin, Study on the metal-support interaction in the Ru/C catalysts under reductive conditions, Surfaces and Interfaces. 12 (2018) 95-101. doi:https://doi.org/10.1016/j.surfin.2018.05.003.

[11] F. Rodríguez-Reinoso, The role of carbon materials in heterogeneous catalysis, Carbon N. 
Y. 36 (1998) 159-175. doi:10.1016/S0008-6223(97)00173-5.

[12] B. Xing, G. Yang, H. Chen, X. Liu, Catalytic wet oxidation of high concentration formaldehyde wastewater over Pt / nitrogen-doped activated carbon, Reac Kinet, Mech Cat. 126 (2019) 547-560. doi:10.1007/s11144-018-1480-3.

[13] J. Zhu, S.A.C. Carabineiro, D. Shan, J.L. Faria, Y. Zhu, J.L. Figueiredo, Oxygen activation sites in gold and iron catalysts supported on carbon nitride and activated carbon, J. Catal. 274 (2010) 207-214. doi:https://doi.org/10.1016/j.jcat.2010.06.018.

[14] X. Zhang, Z. Lu, G. Xu, T. Wang, D. Ma, Z. Yang, L. Yang, Single Pt atom stabilized on nitrogen doped graphene: $\mathrm{CO}$ oxidation readily occurs via the tri-molecular Eley-Rideal mechanism, Phys. Chem. Chem. Phys. 17 (2015) 20006-20013. doi:10.1039/C5CP01922B.

[15] P. Schlexer, D. Widmann, R.J. Behm, G. Pacchioni, CO Oxidation on a Au/TiO2 Nanoparticle Catalyst via the Au-Assisted Mars-van Krevelen Mechanism, ACS Catal. 8 (2018) 6513-6525. doi:10.1021/acscatal.8b01751.

[16] C. Wang, X.K. Gu, H. Yan, Y. Lin, J. Li, D. Liu, W.X. Li, J. Lu, Water-Mediated MarsVan Krevelen Mechanism for CO Oxidation on Ceria-Supported Single-Atom Pt1 Catalyst, ACS Catal. 7 (2017) 887-891. doi:10.1021/acscatal.6b02685.

[17] S. Gatla, D. Aubert, V. Flaud, R. Grosjean, T. Lunkenbein, Facile synthesis of high-surface area platinum-doped ceria for low temperature CO oxidation, Catal. Today. 333 (2019) 105-112. doi:10.1016/j.cattod.2018.06.032.

[18] S. Gatla, D. Aubert, G. Agostini, O. Mathon, S. Pascarelli, T. Lunkenbein, M.G. Willinger, H. Kaper, Room-Temperature CO Oxidation Catalyst: Low-Temperature Metal-Support 
Interaction between Platinum Nanoparticles and Nanosized Ceria, ACS Catal. 6 (2016) 6151-6155. doi:10.1021/acscatal.6b00677.

[19] R. Kopelent, J. van Bokhoven, J. Szlachetko, J. Edebeli, C. Paun, M. Nachtegaal, O. V. Safonova, Catalytically Active and Spectator $\mathrm{Ce}^{3+}$ in Ceria-Supported Metal Catalysts, Angew. Chem. Int. Ed. 54 (2015) 8728-8731. doi:10.1002/anie.201503022.

[20] A. Bruix, A. Migani, G.N. Vayssilov, K.M. Neyman, J. Libuda, F. Illas, Effects of deposited Pt particles on the reducibility of CeO2(111)., Phys. Chem. Chem. Phys. 13 (2011) 1138411392. doi:10.1039/c1cp20950g.

[21] M. Hatanaka, N. Takahashi, T. Tanabe, Y. Nagai, K. Dohmae, Y. Aoki, T. Yoshida, H. Shinjoh, Ideal Pt loading for a Pt/CeO2-based catalyst stabilized by a Pt-O-Ce bond, Appl. Catal. B Environ. 99 (2010) 336-342. doi:10.1016/j.apcatb.2010.07.003.

[22] G.N. Vayssilov, Y. Lykhach, A. Migani, T. Staudt, G.P. Petrova, N. Tsud, T. Skála, A. Bruix, F. Illas, K.C. Prince, V. Matolín, K.M. Neyman, J. Libuda, Support nanostructure boosts oxygen transfer to catalytically active platinum nanoparticles., Nat. Mater. 10 (2011) 310-5. doi:10.1038/nmat2976.

[23] Y. Cao, S. Mao, M. Li, Y. Chen, Y. Wang, Metal/Porous Carbon Composites for Heterogeneous Catalysis: Old Catalysts with Improved Performance Promoted by NDoping, ACS Catal. 7 (2017) 8090-8112. doi:10.1021/acscatal.7b02335.

[24] H. Kaper, A. Grandjean, C. Weidenthaler, F. Schüth, F. Goettmann, Surface Diels-Alder Reactions as an Effective Method to Synthesize Functional Carbon Materials, Chem. - A Eur. J. 18 (2012) 4099-4106. doi:10.1002/chem.201102718. 
[25] Z. Li, W. Yan, S. Dai, Surface functionalization of ordered mesoporous carbons - A comparative study, Langmuir. 21 (2005) 11999-12006. doi:10.1021/la051608u.

[26] P. Zhang, J. Zhang, S. Dai, Mesoporous Carbon Materials with Functional Compositions, Chem. - A Eur. J. 23 (2017) 1986-1998. doi:10.1002/chem.201602199.

[27] H. Chen, F. Sun, J. Wang, W. Li, W. Qiao, L. Ling, D. Long, Nitrogen doping effects on the physical and chemical properties of mesoporous carbons, J. Phys. Chem. C. 117 (2013) 8318-8328. doi:10.1021/jp4017773.

[28] X. Wang, K. Maeda, A. Thomas, K. Takanabe, G. Xin, J.M. Carlsson, K. Domen, M. Antonietti, A metal-free polymeric photocatalyst for hydrogen production fromwater under visible light, Nat. Mater. 8 (2008) 76-80. doi:10.1038/NMAT2317.

[29] A. Khan, M. Goepel, J.C. Colmenares, R. Gla, Chitosan-Based N - Doped Carbon Materials for Electrocatalytic and Photocatalytic Applications, ACS Sustain. Chem. Eng. 8 (2020) 4708-4727. doi:10.1021/acssuschemeng.9b07522.

[30] P. Xiao, Y. Zhao, T. Wang, Y. Zhan, H. Wang, J. Li, A. Thomas, J. Zhu, Polymeric Carbon Nitride / Mesoporous Silica Composites as Catalyst Support for Au and Pt Nanoparticles, Chem. Eur. J. 20 (2014) 2872-2879. doi:10.1002/chem.201303741.

[31] C. Pu, J. Zhang, G. Chang, Y. Xiao, X. Ma, J. Wu, T. Luo, K. Huang, S. Ke, J. Li, X. Yang, Nitrogen precursor-mediated construction of $\mathrm{N}$-doped hierarchically porous carbonsupported Pd catalysts with controllable morphology and composition, Carbon N. Y. 159 (2020) 451-460. doi:10.1016/j.carbon.2019.12.058.

[32] S. Kundu, Y. Wang, W. Xia, M. Muhler, Thermal Stability and Reducibility of Oxygen- 
Containing Functional Groups on Multiwalled Carbon Nanotube Surfaces : A Quantitative High-Resolution XPS and TPD / TPR Study, J. Phys. Chem. C. 112 (2008) 16869-16878. doi:10.1021/jp804413a.

[33] M. Seredych, D. Hulicova-jurcakova, G. Qing, T.J. Bandosz, Surface functional groups of carbons and the effects of their chemical character, density and accessibility to ions on electrochemical performance, Carbon N. Y. 6 (2008) 1475-1488. doi:10.1016/j.carbon.2008.06.027.

[34] X. Ning, Y. Li, B. Dong, H. Wang, H. Yu, F. Peng, Y. Yang, Electron transfer dependent catalysis of Pt on N-doped carbon nanotubes: Effects of synthesis method on metal-support interaction, J. Catal. 348 (2017) 100-109. doi:10.1016/j.jcat.2017.02.011.

[35] A. Boubnov, S. Dahl, E. Johnson, A.P. Molina, S.B. Simonsen, F.M. Cano, S. Helveg, L.J. Lemus-Yegres, J.D. Grunwaldt, Structure-activity relationships of Pt/Al $2 \mathrm{O} 3$ catalysts for CO and NO oxidation at diesel exhaust conditions, Appl. Catal. B Environ. 126 (2012) 315325. doi:10.1016/j.apcatb.2012.07.029.

[36] J. Liu, W. Li, L. Duan, X. Li, L. Ji, Z. Geng, K. Huang, L. Lu, L. Zhou, Z. Liu, W. Chen, L. Liu, S. Feng, Y. Zhang, A Graphene-like Oxygenated Carbon Nitride Material for Improved Cycle-Life Lithium/Sulfur Batteries, Nano Lett. 15 (2015) 5137-5142. doi:10.1021/acs.nanolett.5b01919.

[37] J.A. Singh, S.H. Overbury, N.J. Dudney, M. Li, G.M. Veith, Gold Nanoparticles Supported on Carbon Nitride: Influence of Surface Hydroxyls on Low Temperature Carbon Monoxide Oxidation, ACS Catal. 2 (2012) 1138-1146. doi:10.1021/cs3001094. 
[38] M. Inagaki, M. Toyoda, Y. Soneda, T. Morishita, Nitrogen-doped carbon materials, Carbon N. Y. 132 (2018) 104-140. doi:https://doi.org/10.1016/j.carbon.2018.02.024. 